\title{
LOS SISTEMAS DE ARMAMENTO VISLUMBRADOS EN LAS FIGURAS DE GUERREROS DEL OCCIDENTE DE MÉXICO
}

\author{
POR
}

\author{
Marco Antonio Cervera Obregón*
}

\begin{abstract}
RESUMEN - ABSTRACT
El siguiente trabajo esboza algunos de los pormenores actuales sobre el estudio de la guerra y armamento en la macroregión cultural designada como Mesoamérica. Presenta en forma concreta el caso de la subárea cultural del Occidente de México, proponiendo como principal indicador arqueológico para conocer el fenómeno de la guerra, los sistemas de armamento y las tácticas militares en los periodos Preclásico y Clásico, a las representaciones de guerreros reconocidas como parte del contexto arqueológico de las llamadas Tumbas de Tiro. El estudio se basa en un análisis iconográfico y del diseño de los artefactos que portan dichas manifestaciones artísticas, considerando las respectivas limitaciones arqueológicas que en conjunto presenta la región.
\end{abstract}

The following work outlines some of the present details on the study of the war and armament in the designated cultural region like Mesoamérica. It presents in form makes specific the case of the cultural subarea of the West of Mexico, proposing like main archaeological indicator to know the phenomenon the war, the weapons and military tactics in the Preclassic and Classic periods, to the representations of soldiers recognized like part of the archaeological context of the calls Tumbas de Tiro. The study is based on a icongraphic analysis and of the design of the devices that carry these artistic manifestations, considering the respective archaeological limitations that altogether the region.

\section{PALABRAS ClaVe - KeYWORdS}

Armamento. Arqueología. Mundo Precolombino. Occidente. México

Weapons. Archaeology. Precolumbian World. West. México

\section{MESOAMÉRICA Y EL ESTUDIO DE LA GUERRA PRECOLOMBINA, ESTADO GENERAL DE LA CUESTIÓN}

Lo que actualmente se ha dado en llamar como México Antiguo estuvo integrado por tres subáreas culturales bien diferenciadas: Aridamérica, Oasisamérica y Mesoamérica. Esta última que comprende parte del norte, centro y sur del actual territorio mexicano incluyó algunas porciones de otros países como son Honduras, Guatemala y Belice. Mesoamérica es a la fecha la región más conocida de las tres y para facilitar su estudio ha sido dividida geográfi-

\footnotetext{
* Arqueólogo por la Escuela Nacional de Antropología e Historia de México.
} 
camente en pequeñas regiones conocidas como: La Costa del Golfo, La zona Maya, Oaxaca, El Altiplano Central y el Occidente de México. La diversidad política y cultural de Mesoamérica no fue una unidad como se podría pensar, por el contrario, esta macro área geográfico-cultural estuvo habitada por un sin fin de grupos indígenas de muy variadas lenguas y manifestaciones sociales que a su vez compartían ciertos rasgos que en cierta forma permiten establecer una cierta homogeneidad cultural que ya antes el investigador Paul Kirchoff había definido.

La historia cultural de Mesoamérica tiene sus antecedentes desde hace más de 35,000 años con las poblaciones cazadoras-recolectoras de la etapa prehistórica sin embargo lo que a nuestro interés respecta, el estudio de la guerra y armamento de la región no empieza a generarse sino hasta el desarrollo de las sociedades sedentarias que terminaron por fundar pequeñas aldeas con un sistema de subsistencia encaminado más hacia la agricultura, complementada con la caza, pesca y recolección. En este momento ya estaríamos hablando de sociedades que sentarían las bases de las futuras culturas mesoamericanas como la maya, azteca o teotihuacana por citar algunos ejemplos. Esta etapa conocida como periodo Preclásico (2500 a.C. al 100 d.C) es donde podamos comenzar a reconocer algunos indicadores arqueológicos de la práctica de la guerra. Parte de estos indicadores pueden estar registrados en los monumentos escultóricos, piezas cerámicas con la representación de guerreros armados, o bien en los instrumentos líticos y de madera como evidencia directa de su armamento. También parte de este registro puede estar presente en sus construcciones que permiten explicar algunos aspectos del arte de la poliorcética mesoamericana ${ }^{1}$ como son palizadas, fosos, sitios fortificados o asentamientos localizados en zonas estratégicas de defensa ubicadas en las zonas altas de los cerros. La antropología física también puede proporcionar datos a partir de la evidencia de restos óseos con huellas de violencia tema que aun esta en proceso de desarrollo.

Durante el Preclásico sobre todo en algunas áreas concretas como en la zona maya la guerra comenzaba a jugar un papel importante en el desarrollo político y cultural de este pueblo, sin embargo no en toda Mesoamérica durante este periodo resulta tan claro, sobre todo por la falta de indicadores y por la falta de estudios que centren su atención en este fenómeno. En Oaxaca existe la representación de los denominados danzantes, personajes hipotéticamente capturados en batalla que se esculpieron en algunas estelas. Se les representa totalmente desnudos con el sexo mutilado (Fig. 1). Dichas estelas se transforman en elementos arquitectónicos en la ciudad de Monte Albán para enaltecer las conquistas de los alrededores de la ciudad. Prueba de ello también son una serie de glifos tallados en la fachada del edificio $\mathrm{J}$, los cuales representan los topónimos de diversos lugares conquistados por dicha ciudad. En ellos se ve la representación de un cerro el cual designa el concepto de "pueblo" muchas veces acompañados de una flecha inserta o el rostro de un personaje que sobresale por la parte inferior del glifo, ambos, denotando la idea de conquista (León Portilla, 2004, 27 28). Hay otras áreas que pueden realmente estar en discusión respecto a los indicadores arqueológicos propuestos como punto de análisis de la guerra para este periodo, tal es el caso del Altiplano Central donde se ha encontrado un fémur humano con una punta de proyectil incrustado, presumiblemente derivado de un conflicto armado (Ochoa y Orueta, 1994:196) y la Costa del Golfo en la que algunos monumentos escultóricos como el monumento $\mathrm{C}$ de Tres Zapotes registran la imagen de algunos guerreros combatiendo con mazos y lanzas defendiéndose con escudos rectangulares (Hassig, 1992: 31). Los fragmentario de las evidencias parecen insuficientes para reconstruir de una forma realmente fiable el fenómeno de la gue-

\footnotetext{
${ }^{1}$ El asunto de la poliorcética mesoamericana es uno de los temas que merece mayor atención en la actualidad, son pocos los trabajos que se han desarrollado en este sentido. Debo recomendar algunas pequeñas publicaciones de autores como Pedro Armillas y David Webster.
} 
rra en la mayor parte de las sociedades del Preclásico, pese a ello algo se puede avanzar si se estudia con detenimiento los pocos recursos de que disponemos y sin duda es necesario un mayor interés por tratar de determinar estos factores en otras regiones como veremos en el caso del Occidente de México.

Entrado el periodo Clásico (100 -900 d.C.) las evidencias del militarismo son bastante claras en varias de las regiones. Mucho del material que se registra en las estelas de la zona



1.- Este tipo de estelas conocidas como "danzantes" representan a personajes capturados y sacrificados, presentados como trofeos de guerra. Procede de Monte Albán, Oaxaca. 
maya por ejemplo, nos hablan de una serie de conflictos entre los pequeños señoríos, evidenciados por el sometimiento y captura de prisioneros o la destrucción misma de grandes ciudades. Dentro de la pintura mural se comienzan a representar grandes batallas donde es factible reconocer el sistema de armamento de los ejércitos en disputa como en el caso de las pinturas murales de Bonampak (Fig. 2).También en la zona maya durante el periodo Clásico se han comenzado recientemente a encontrar campos de batalla que ayudarán a esclarecer parte de los últimos años de la cultura maya en este periodo, el caso concreto de Cancuén donde se han encontrado los cuerpos descuartizados de más de treinta miembros de la nobleza maya, parte de este hallazgo esta complementado con el estudio de empalizadas inacabadas, construcciones destruidas, material lítico como puntas proyectil y lanzas dispersas así como restos óseos con huellas de violencia.

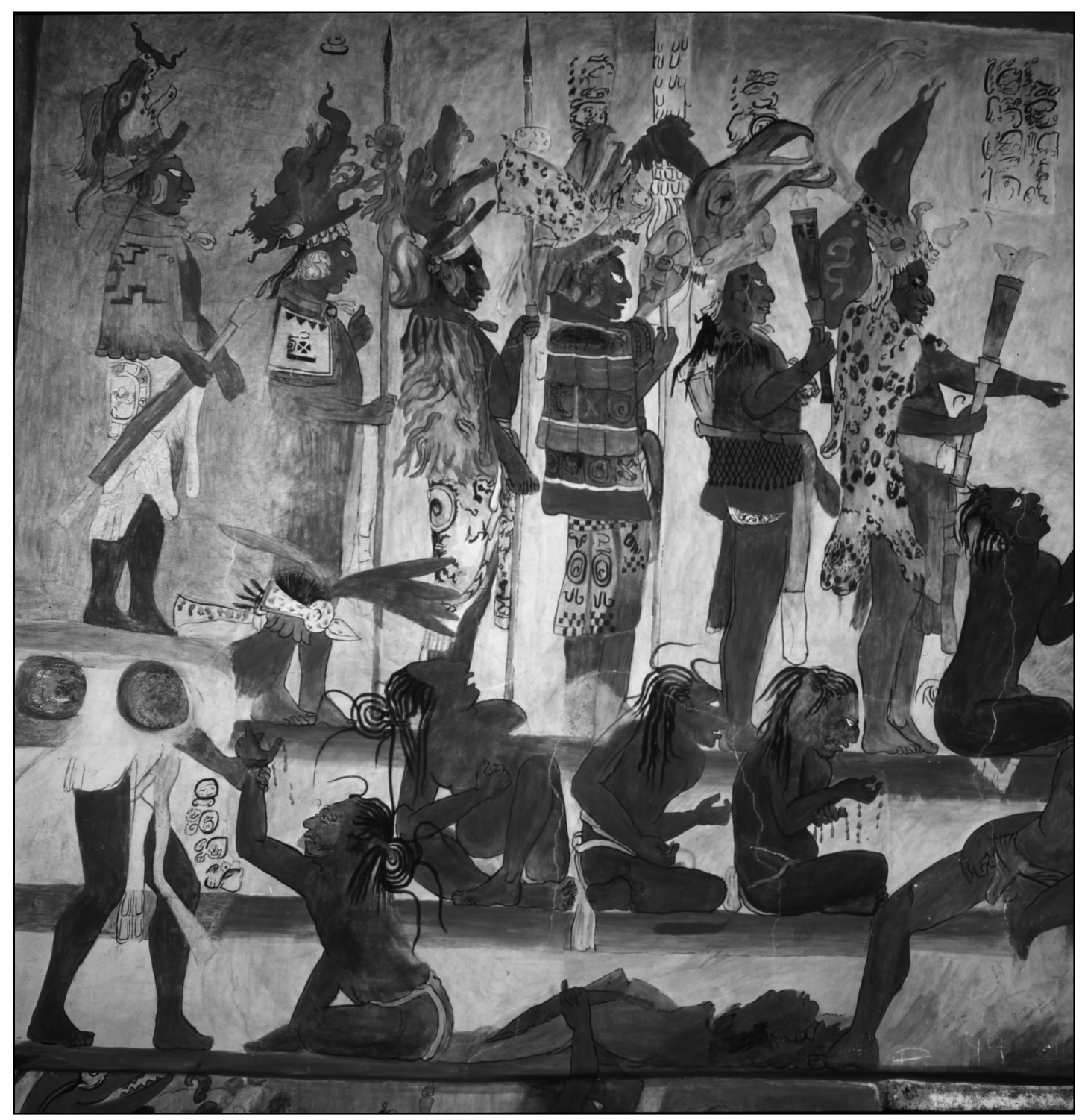

2.- En esta escena unos cautivos están siendo entregados a un gobernante maya el cual porta una lanza como arma principal, típico de la época Clásica. Bonampak, Chiapas. 
Otras culturas como la teotihuacana en el Altiplano Central empiezan a ser motivo de una producción cada vez más creciente y en ocasiones polémica sobre el tema de la guerra, derivado de los recientes hallazgos en la ciudad llevados a cabo por Rubén Cabrera, Saburo Sugiyama, Linda Manzanilla y Leonardo López Luján en conjunto con su equipo de investigadores. El creciente análisis de restos óseos con huellas de haber sido participes de macabros rituales de sacrificio, las diversas representaciones de guerreros tanto en pintura mural y figurillas cerámicas comienzan a reevaluarse bajo trabajos de autores como Claudia Des Lauries (García Des Lauriers, 2000), y de otros nuevos investigadores así como en las actuales Mesas Redondas sobre Teotihuacan en donde el problema del militarismo empieza a ser un nuevo punto de partida para conocer el estamento político y sus relaciones culturales con pueblos tan alejados como el maya. (Sugiyama, 2002).

Llegado el periodo Posclásico para el año 900 d.C., las manifestaciones de guerra son abrumadoras en ciudades como Tula, muchas y variadas son las representaciones en piedra de guerreros sujetando armas. Águilas, zopilotes y jaguares aparecen como decoración de los edificios principales devorando corazones de sacrificados y los mismos dioses y gobernantes como Quetzalcóatl y Tláloc aparecen representados como grandes guerreros armados sobre todo con propulsores. Resalta el hecho que no exista un estudio detallado dedicado a explicar los aspectos concretamente militares de esta sociedad que en su simple evidencia material es rica de información y que puede abrir muchas posibles interpretaciones.

Debemos destacar que para esta época ya no solamente se cuenta con la evidencia arqueológica sino que también se tienen documentos pictográfcios y fuentes históricas que en muchas ocasiones ayudan a ser una fuente muy importante de investigación sobre el militarismo mesoamericano de este último periodo. Es gracias a esta variada fuente de información y los hallazgos arqueológicos que muchas sociedades de la segunda mitad del periodo Posclásico, entre ellos pueblos como el mixteco, maya y sobre todo el azteca han sido motivo de variadas investigaciones sobre diversos temas del miltarismo como son asuntos generales sobre la guerra, los ejércitos, las tácticas militares y el armamento con autores como José Lameiras (1985), Ross Hassig (1988), John Pohl (1991, 2001), Beatríz Reppeto (1993) Isabel Bueno (2006) y quien esto suscribe , Cervera, (2003, 2004, 2006, 2007).

Son varios los trabajos generales que pueden ser consultados para conocer el problema del militarismo en Mesoamérica, autores como Ross Hassig quien a la fecha es una de las principales autoridades en el tema y su libro War and Society in Ancient Mesoamerica sigue siendo una referencia general obligada, así como los recientes trabajos sobre la guerra en la zona maya derivada de las mesas redondas de Palenque con el trabajo publicado en el año 2005 titulado La guerra entre los mayas. Memoria de la Primer Mesa Redonda de Palenque. Uno de los más recientes trabajos compilatorios y que deja abierta un sin fin de posibilidades de investigación en Mesoamérica es el titulado como Ancient Mesoamerican Warfare, publicado en el año 2003. ${ }^{2}$

Pese a lo antes reseñado el Occidente de México esta aun en una gran laguna académica que debe ser superada en torno al problema de los estudios sobre guerra mesoamericana, aspecto que veremos a continuación.

\footnotetext{
2 Para mayor información sobre el estado de la cuestión sobre la guerra en Mesoamérica se recomienda consultar la Bibliografía selecta sobre la guerra en Mesoamérica, de Marco Cervera ubicada en el sitio web www.naya.com.ar . Esta bibliografía solo abarca hasta el momento de su publicación, 2001 pese a ello actualmente aun esta en proceso de actualización para ser republicado en otro trabajo.
} 


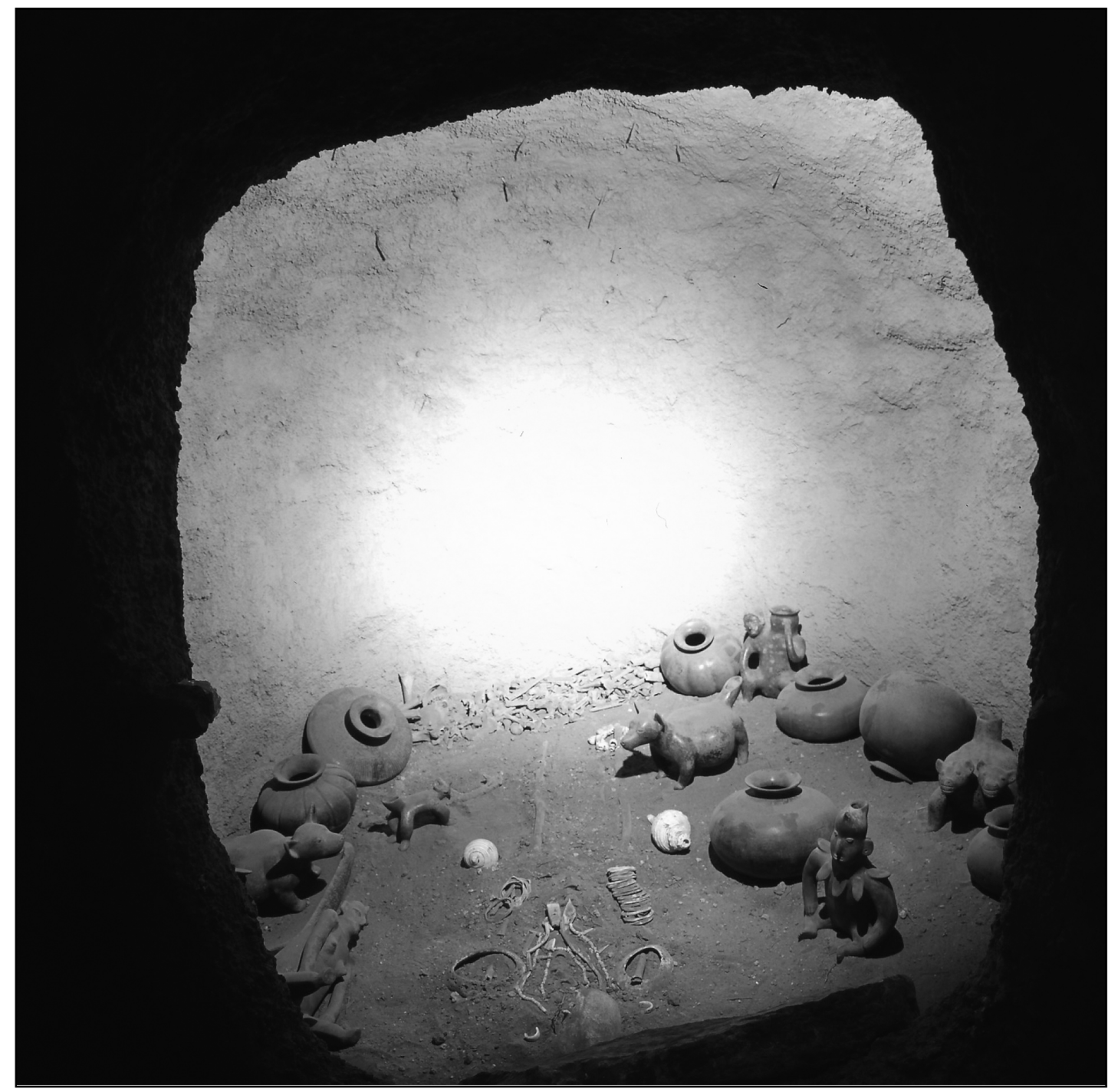

3.- Tumba de tiro. Jalisco.

\section{LA ARQUEOLOGÍA DEL OCCIDENTE DE MÉXICO}

La subárea mesoamericana denominado por los arqueólogos como Occidente de México a sufrido desde hace ya varios años diferentes modificaciones con respecto a su delimitación geográfica. Originalmente se trataba de una extensión territorial que debido a la supuesta homogeneidad cultural de los pueblos prehispánicos que las habitaron se consideraba comprendido por los siguientes estados mexicanos: Nayarit, Colima, Michoacán, Jalisco, Sinaloa y en algún tiempo Guerrero, sin embargo ahora sabemos que por la problemática arqueológica y características específicas de los hallazgos arqueológicos en este último estado, es difícil insertarlo en el concepto de "Occidente de México". (Shöndube, 1994: 19). Pese a ello en algunos trabajos recientes desarrollados por los especialistas de la zona han determinado circunscribir al área del occidente mexicano fragmentos de otros estados poco estudiados como 
son Guanajuato, Aguascalientes y Durango. Sea como fuere el territorio que actualmente comprende la mayor parte de estos estados estuvo habitado por una diversidad cultural que en mucho se ha diferenciado a las tradiciones civilizatorias de la antigua Mesoamérica.

Temporalmente se tiene un registro cultural que va desde el periodo Preclásico cuya fecha aproximada de inicio va para el año 2000 a.C. hasta iniciado la era cristiana aproximadamente, pasando por el periodo Clásico de los años 100 a 1200 d.C. hasta culminar con el desarrollo y desaparición de culturas como la de Eztatlán y tan representativas como la tarasca en el periodo Posclásico entre los años 1200 a 1500 d.C. ${ }^{3}$ El resultado de las relaciones culturales internas del propio occidente combinado con las de otras regiones de Mesoamérica e incluso con zonas de otros países como Ecuador y Perú, de los cuales importan la tecnología de los metales durante los últimos años de su historia prehispánica (López Austin, 1996: 261), crean finalmente una gama cultural muy variada y rica que aun esta en un largo y casi inagotable proceso de investigación.

Así también como existió cierta unidad cultural en el territorio comentado, también existieron desarrollos culturales locales que sirvieron de base para crear en cada territorio sobre todo excelentes manifestaciones plásticas de su cultura, en especial en lo referente a las artes menores como la cerámica, metales y en pocas ocasiones escultura en piedra. Esto contrasta notablemente con las pocas manifestaciones de una arquitectura de grandes dimensiones como sucede en otros puntos mesoamericanos como Teotihuacan o la zona maya, es decir, poco se ha encontrado de grandes construcciones a manera de basamentos escalonados o pirámides en la región del Occidente, ello no quiere decir que no existan del todo. Por el contrario se han encontrado interesantes complejos arquitectónicos de planta circular y mixta que se han englobado bajo la tradición denominada Teuchitlán y comúnmente conocidos como guachimontones.

Algunas de las tradiciones culturales de mayor relevancia en estados como Colima han sido datados en una antigüedad hacia el siglo XVIII a.C. bajo la denominación de cultura Capacha caracterizada por un tipo de vasijas cerámicas alargadas de cintura muy estrecha (Ibidem, 93).

A finales del periodo Preclásico surge en los estados de Jalisco, Colima y Michoacán principalmente la tradición de las Tumbas de Tiro, tradición que entre otras cosas se caracteriza por la creación de grandes tumbas excavadas en el tepetate y de las que tendremos oportunidad de ampliar más detenidamente en párrafos siguientes.

Durante el Clásico, las relaciones del Occidente con el resto de Mesoamérica fue muy pobre, prácticamente algunas manifestaciones culturales como la antes descritas de las Tumbas de Tiro se extendieron por lo menos hasta el siglo VI d.C. siendo una de las más representativas del momento. Algunas otras menos estudiadas como la cultura del Bajío, desarrollada en el estado de Guanajuato tuvieron a bien desarrollar algunos edificios y objetos cerámicos de especial belleza (Fernández, 2005).

Para los últimos siglos de la historia prehispánica del Occidente en el Posclásico algunos centros de relativa magnificencia como Ixtlán del Río, Eztatlán, el Chanal estuvieron enfrascadas en pequeñas guerras. Durante el periodo Posclásico, fue el estado Tarasco el que sobre todo llevó la mayor unificación y desarrollo de la región. Considerado uno de los pueblos más belicosos de Mesoamérica, esta civilización creó un basto imperio que fue el principal rival del estado azteca durante este horizonte. Sin duda es este uno de las principales minas de oro para la investigación mesoamericana y especialmente en el Occidente mexicano para el estudio de la guerra en tiempos precolombinos, sin embargo como veremos a continuación existen muchos aspectos en contra para poder realmente hablar de algún estudio concreto y claro sobre la guerra en el Occidente prehispánico de México.

${ }^{3}$ Existen autores que consideran que el inicio del Posclásico en el Occidente se da en año el 600 d.C. con la culminación de las culturas de Tumbas de Tiro (López A., 1996:261). 


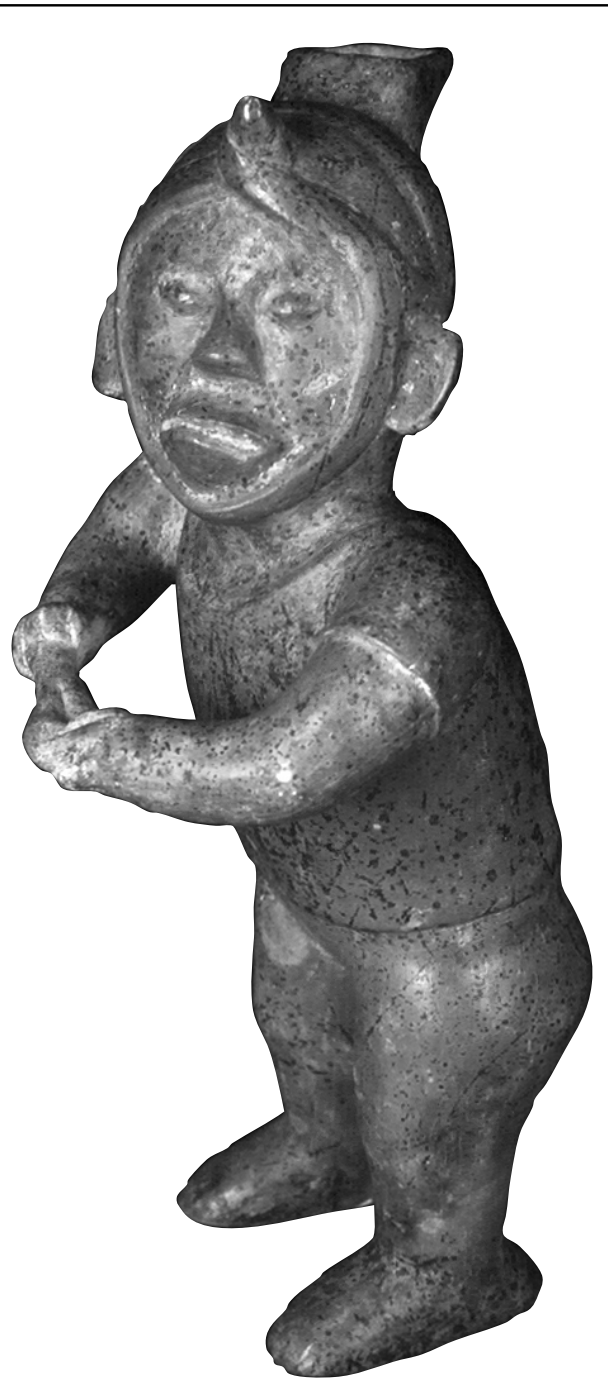

4.- Guerrero en el momento de estar preparando un proyectil para ser arrojado con una honda. Museo Regional de Guadalajara, Jalisco, México.

\section{EL FENÓMENO DE LA GUERRA EN EL OCCIDENTE DE MÉXICO}

La información que tenemos de la actividad militar en Mesoamérica es hasta el momento bastante satisfactoria como ya hemos visto, sobre todo en sociedades como los mexicas o mayas, y recientemente comienza a generarse algo interesante en Teotihuacan. Entre tanto y como era de esperar, el caso del Occidente de México peca de estar casi completamente virgen en torno a este tema, ellos se debe como sabemos al desafortunado rechazo que ha sufrido por los investigadores durante ya varios años no solo sobre materia de militarismo son en general a su arqueología. Por otro lado tal parece que la actividad bélica no fue bastante practicada hasta finales del periodo Posclásico, o por lo menos así lo deja ver la información 
arqueológica obtenida hasta el momento. Prácticamente fuera del pueblo tarasco del Posclásico Tardío, del cual sabemos más por fuentes históricas que por la arqueología su intensa actividad militar, producto de los constantes choques con los ejércitos aztecas, realmente ¿que podemos decir de la guerra en el periodo Preclásico y Clásico en las culturas el Occidente mexicano?. El desarrollo cultural de esta región no ha dejado claro, hasta donde sabemos, un proceso de militarización en sus sociedades, no hay un desarrollo de una poliorcética, el hallazgo de algún campo de batalla, las constantes manifestaciones de brutalidad vinculadas al sacrifico humano como en Tenochtitlan o recientemente en Teotihuacan y constantemente atribuidas a la práctica del fenómeno de la guerra. Es quizá en sus expresiones plásticas donde debemos buscar algún posible indicador.

De los antecedentes de investigación que se han trabajado anteriormente referente a esta región en particular poco podemos decir, la mayoría de los pocos autores que han dedicado algunas líneas a este fenómeno en el Occidente prehispánico se han centrado en los últimos años de la historia prehispánica con el caso tarasco como Carlos Herrejón, 1978 por citar un ejemplo. El único investigador que ha presentado una propuesta específica para el área en cuestión es Ross Hassig tanto en el periodo Preclásico y Clásico como para la época tarasca. (Hassig, 1992:197-198, 152-154).

Una de las principales aportaciones del Occidente de México a la cultura material arqueológica mesoamericana son sin duda las extraordinarias figuras que han aparecido en los contextos funerarios de las Tumbas de Tiro, sin embargo un gran inconveniente de esta plástica es que por mucho tiempo se desarrolló toda una industria de falsificaciones que han estado llenado museos y colecciones privadas en todo el mundo, esto aunado a las intensidad de saqueos sistemáticos llevados a cabo en la zona lo que deja al descubierto un importante hueco en el análisis que a continuación abordaremos. De la gran cantidad de tumbas que existen en el Occidente poco más de 32 son las tumbas que confiablemente presentan los datos arqueológicas más claros para la interpretación de estos contextos. Sin embargo es en la representación misma de estas figuras donde encontramos a mi parecer una de los principales indicadores arqueológicos del fenómeno militar en el Occidente en los tiempos más tempranos de la región, me refiero especialmente a la imagen de los guerreros.

Como veremos a continuación la imagen del guerrero en el Occidente dista mucho de ser lo que generalmente se ve en el resto de Mesoamérica, tanto en sus atavíos, sistemas de armamento, actitudes y movimientos, todo ello sin olvidar su contextualización dentro de rituales funerarios específicos de los cuales los especialistas de la zona han dado sus propias versiones de interpretación.

\section{LAS TUMBAS DE TIRO}

Entre los años 200 a.C. al año 650 d.C. se desarrolló principalmente en los estados de Jalisco, Nayarit y Colima el complejo cultural de las Tumbas de Tiro. Ellas se refieren a extensos túneles excavados en el tepetate donde se introducían en cámaras de diferentes formas los restos de individuos que iban a ser acompañados de vistosas ofrendas entre las que se cuentan esculturas de cerámica, algunas sólidas y de gran dimensión generalmente huecas (Figura 3). La diversidad de elementos representados es muy variable pues va desde animales, plantas y personajes antropomorfos. Hasta donde podemos pensar buena parte de las representaciones humanas encontradas como dones en estas ofrendas funerarias, parecen relacionarse con la interpretación que los artistas indígenas hacían de los usos y costumbres de los pueblos creadores mismas que a su vez tenían como objetivo recrear la vida cotidiana de los individuos para que de esta forma efectuaran su viaje al inframundo. El reflejo de estas actividades está presente en todo tipo de personajes plasmados en diversas facetas de su vida 
como pueden ser jugadores de pelota, músicos, sacerdotes, ceramistas o simplemente mujeres y hombres con ciertos atavíos que en gran medida reflejan su rango social y actividad a desempeñar.

Sabemos que los antecedentes sobre la construcción de este tipo de tumbas derivan del Preclásico en sitios como el Opeño. En estos contextos, y sobre todo ya entrado el periodo Clásico, las imágenes de guerreros se acentúan, elaboradas bajo las características de estilos artísticos locales en estados como Colima, Nayarit y Jalisco, especialmente. Para Beatriz de la Fuente los mejores exponentes del arte de las Tumbas de Tiro son las procedentes de Colima desarrollando formas de animales, plantas y humanas entre las que se incluyen los guerreros (De la Fuente, 1982: 418). Las versiones de Nayarit un poco más sobrias, son más anecdóticas de las cuales se desprenden las versiones en maqueta de la vida cotidiana de los pueblos que las elaboraron. Por su parte los ceramistas en Jalisco se restringieron sobre todo al ámbito antropomorfo. De todas ellas la imagen del guerrero especialmente ataviado, suje-

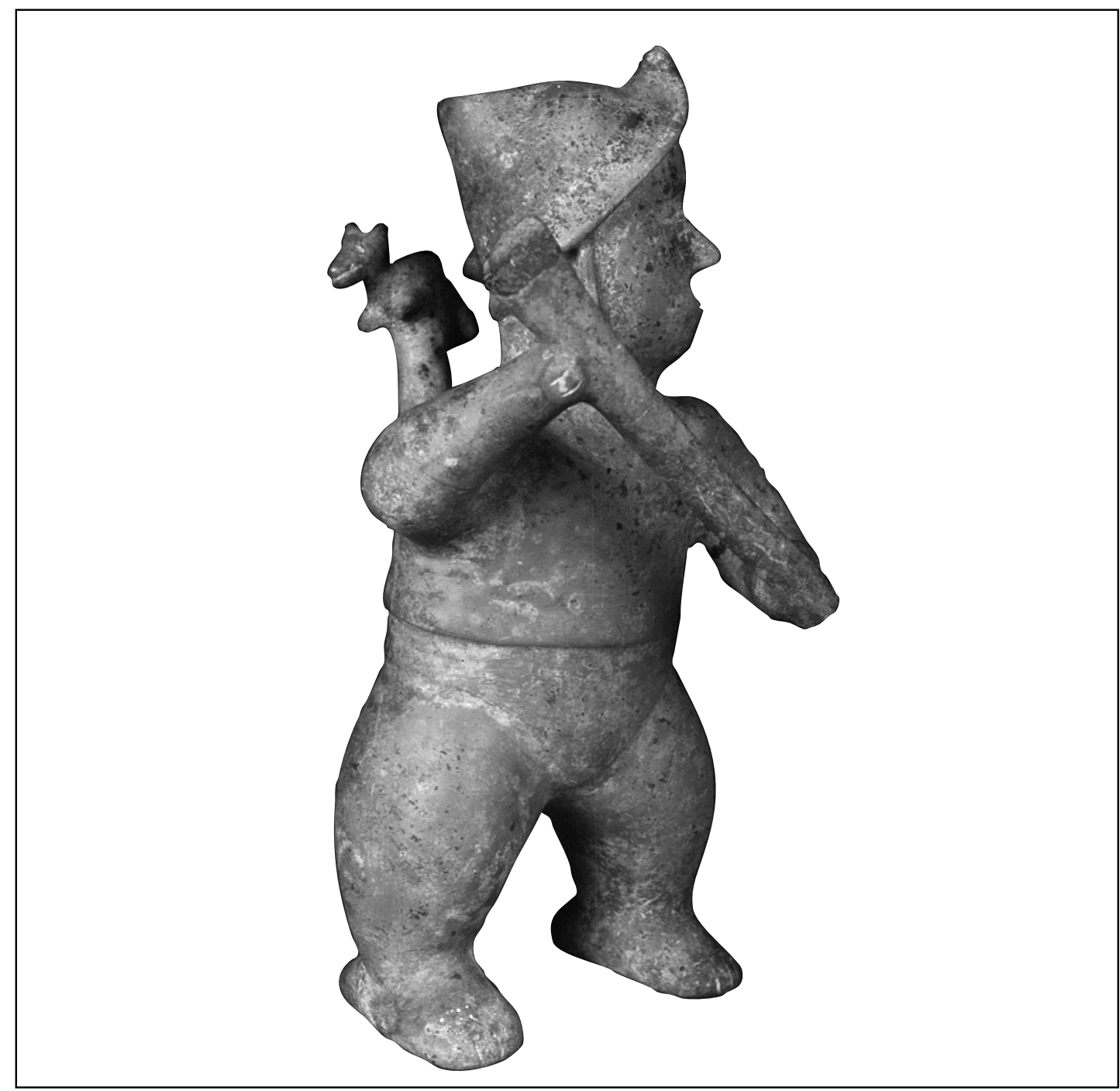

5.- El principal sistema de armamento apreciado en este tipo de figuras es el guerrero con grandes bastones que blanden a manera de mazos. Estado de Jalisco, México. 
tando todo tipo de armas y sobre todo en el momento mismo del combate es generalmente parte de los dones vinculados a este tipo de ofrendas. ¿Debemos tomar estas representaciones como un indicador arqueológico del inicio de la actividad bélica en las sociedades del Occidente?. ¿Estas figuras son el reflejo de un gremio específico dedicados exclusivamente a la guerra o están por el contrario, vinculadas a un complejo ceremonial funerario dentro del cual la figura del guerrero juega un papel preponderante en la vida en el más allá del difunto?. Creo que los dos presupuestos tienen una gran verdad y no se contradicen. Como ya hemos comentado efectivamente este tipo de manifestaciones tenían en principio el objetivo de ser un tipo especial de dones que intentan ser un ajuar que acompañará a los muertos (Solís, 1998:18) es decir lleva en su simple existencia una carga simbólica importante sin embargo derivado de la representación iconográfica por si misma el objetivo fundamental era recrear, gran parte de la vida de los individuos para llegar al inframundo lo que sin duda refleja claramente aspectos cotidianos, en este caso el gremio de los guerreros del Occidente mexicano.

En algunos casos las interpretaciones de estos personajes han sido relacionadas con chamanes más que por la imagen misma de guerreros (Towsend, 2000), (Von Winning, 1974). Sea como fuere en la mayoría de los casos, la interpretación es clara en trono a los atavíos, las armas y sobre todo el dinamismo de la actividad beligerante.

Desde mi particular punto de vista puedo decir que estas figuras se caracterizan a diferencia de otras imágenes de guerreros mesoamericanos por tres aspectos: el patrón claro de un sistema de armamento bastante primitivo comparado con la tecnología militar de sociedades contemporáneas y posteriores a ellas, esta presente la representación de ciertas armas que no aparecen en ninguna otra manifestación de Mesoamérica y que hipotéticamente tiene más relación con las sociedades precolombinas de otras regiones como Ecuador o Perú y finalmente el gran dinamismo con que son expresadas las acciones bélicas.

\section{LOS GUERREROS DEL OCCIDENTE DE MÉXICO}

La gran mayoría de los personajes considerados como guerreros tienen la característica de presentar gran movimiento generalmente en posiciones de ataque y pocas veces en el momento defensivo. Sus movimientos se asocian al uso de armas de corto alcance y gran contundencia. Por el contrario del uso de armas de largo alcance como son arcos, flechas, lanzadardos es poco común salvo el caso específico de la honda.

Existen diversas representaciones de guerreros sujetando esta particular arma que hasta donde sabemos no se encuentra tan comúnmente representada en otro tipo de imágenes mesoamericanas. Generalmente estos personajes aparecen sujetando el lazo en una mano el cual sirve como motor propulsor del proyectil, ya que en la mano contraria esta siendo cargado el instrumento con un proyectil seguramente de piedra o en ocasiones bien pudo haber sido de cerámica (Figura 4).

Entre las armas más comúnmente representadas en estas esculturas se encuentra un tipo de macanas muy sencillas sujetadas en la mayoría de los casos con dos manos lo cual nos puede indicar su posible peso y dificultad para maniobrarlo, ya que los guerreros que sostienen este tipo de armas, generalmente no portan ninguna arma defensiva o alternativa como fuera un escudo (Figura 5 y 7). Además debemos recalcar el posible uso contundente de esta macana, pues no presenta ningún aditamento lítico punzo-cortante, pese a ello existen algunos casos en los cuales si esta presente este tipo de aditamentos para darle mayor capacidad de lesión al artefacto.

La capacidad de movilidad es permitida por el uso de corazas que protegen todo el contorno de la parte media del cuerpo que generalmente deja una mayor movilidad en su interior, 
ya que no están confeccionadas anatómicamente. Por el contrario tenemos otras que parecen ajustarse más al cuerpo del soldado como se aprecia en algunas manifestaciones (Cervera, 2003:24).

Con respecto a los cascos, generalmente están confeccionados a manera de cono truncado invertido que remata en la parte superior por algún tipo de diseño como pueden ser plumas, o dos protuberancias. En otros casos el yelmo protege la cabeza hasta la nuca como el hondero de Nayarit (Gendrop, 1988: 22).

Existen así también imágenes de personajes sujetando grandes lanzas que están a punto de ser utilizadas sobre su oponente y protegidos completamente por corazas probablemente de cuero.

El caso de los escudos que como he dicho es poco lo representado en este tipo de plástica. Se puede diferenciar claramente dos tipos: Los escudos circulares comúnmente llamados "rodelas" y los de tipo rectangular. Ejemplo de ello son las imágenes de dos guerreros que portan en una de sus manos una roca dispuesta a ser arrojada y en la otra un escudo de gran dimensión que los protege en toda la sección media e inferior del cuerpo ya que su cabeza está resguardada por un yelmo (Figura 6).

Lo que queda muy claro es que existe un fuerte patrón para determinar con toda claridad los sistemas armamentistas de estos personajes, considerado tan solo por el estudio de la representación de sus armas y atavíos como grupos de choque de gran potencia.

Pero no siempre los guerreros aparecen solos en posiciones de combate, existen ejemplares en los cuales la participación de dos oponentes entrañando algún tipo de combate. Un

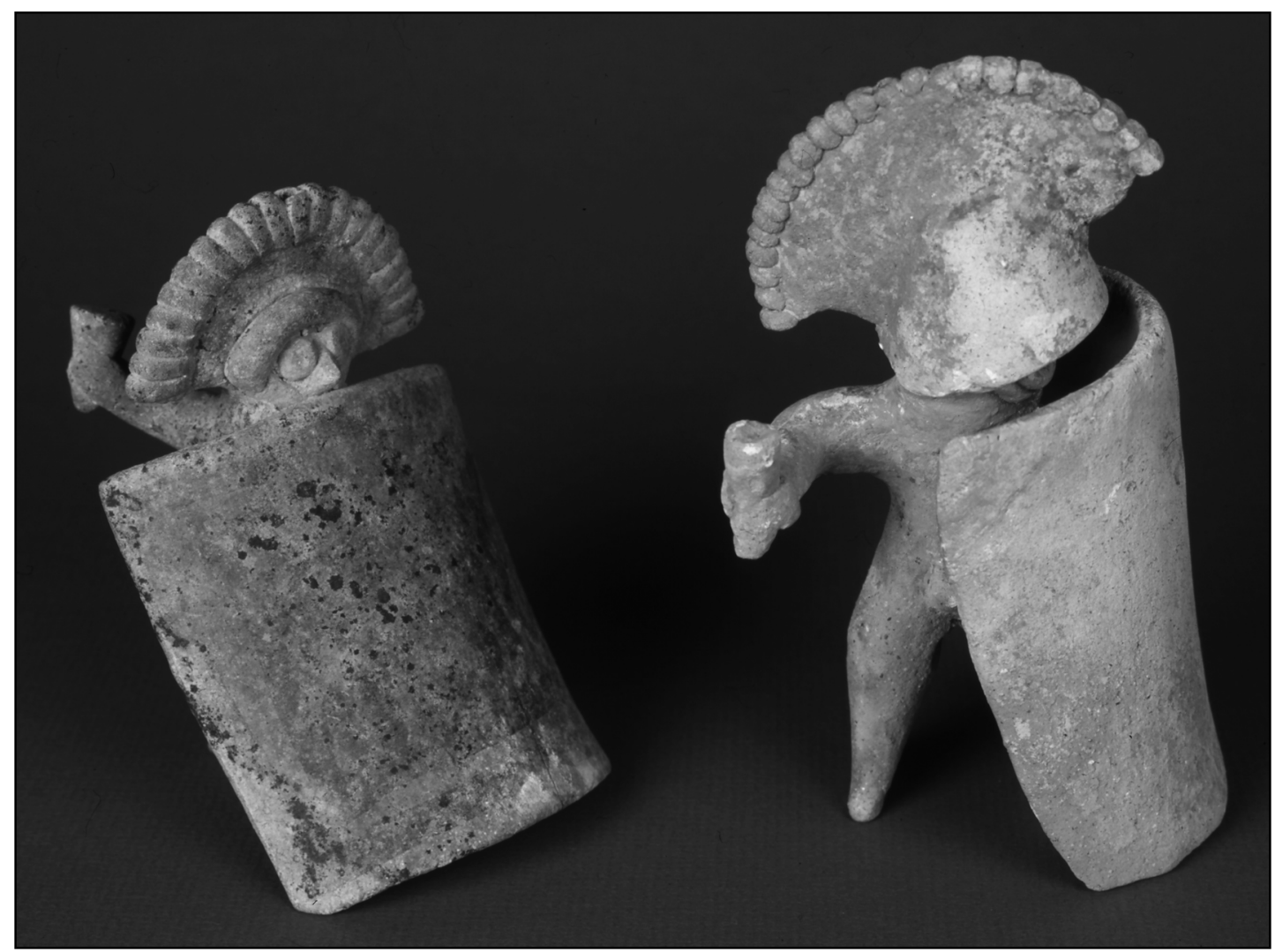

6.- Guerreros en combate se protegen por dos grandes escudos de los proyectiles de piedra que están por arrojares 
caso por demás interesante y polémico es el de dos guerreros pertenecientes al Museo Regional de Guadalajara donde los ceramistas de la región tuvieron la delicadeza de expresar el combate de un primer personaje que sujeta de los cabellos a un segundo, mismo que tirado en el suelo, esta a punto de recibir un golpe por parte de su oponente utilizando como medio de ataque una simple piedra (Solís, 1998: 86).

Sabemos por otros vestigios en Teotihuacan y en la zona maya que algunas sociedades del Clásico practicaron la captura de prisioneros durante sus guerras, no esta del todo claro que las sociedades del clásico y mucho menos del Preclásico practicaran algún tipo de guerra florida como la versión azteca, pese a ello las evidencias de captura y sometimiento de sus enemigos es clara. Las representaciones de guerreros del Occidente no escapa a ello o por lo menos eso nos deja ver un ejemplar que resulta sugerente al encontrar un guerrero que sujeta en una de sus manos un cuchillo y de la otra sujeta de los cabellos a un segundo tirado a gatas.

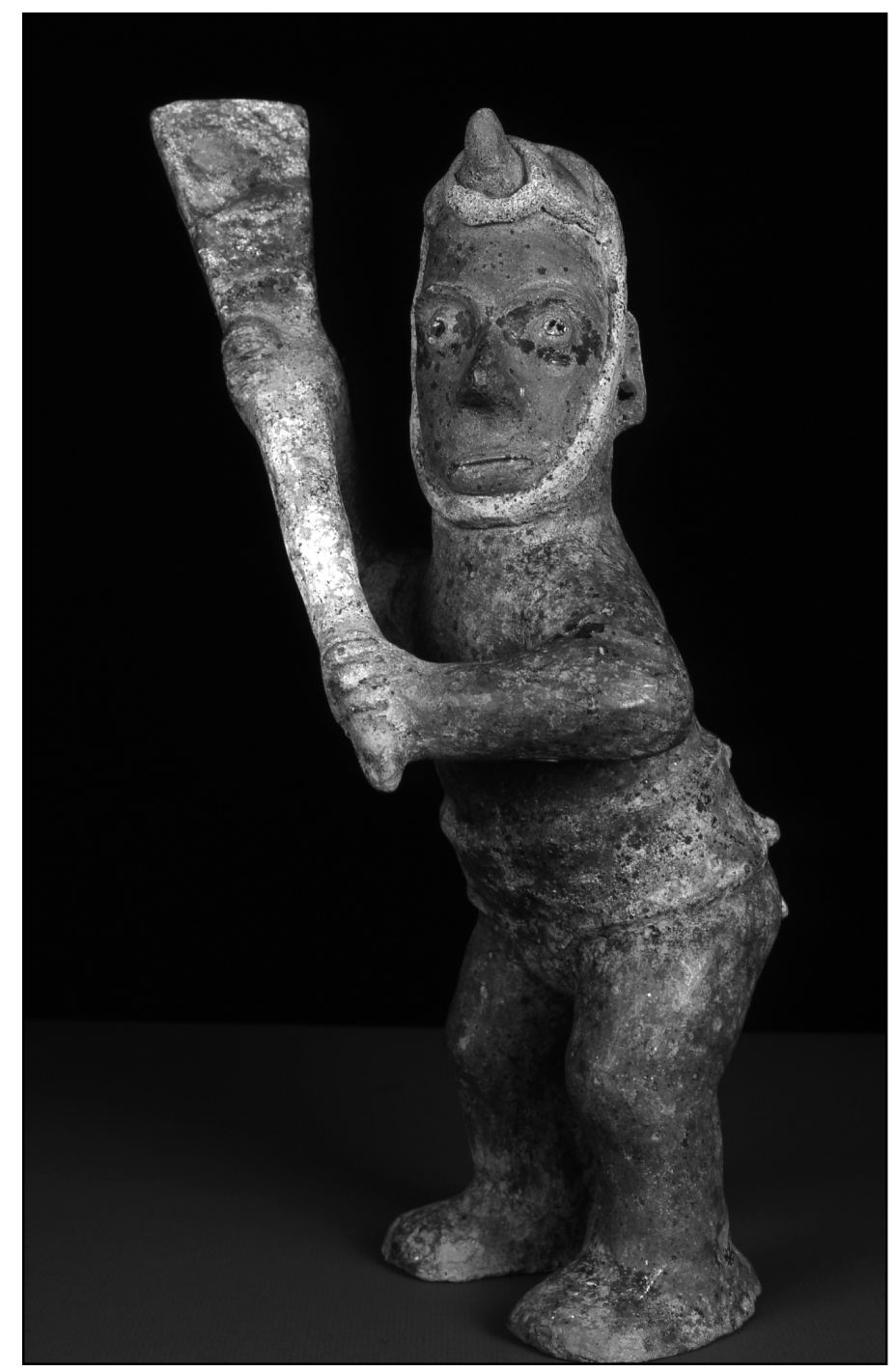

7.- Guerrero sujetando un tipo especial de mazo. 
La manufactura de piezas tridimensionales que escenifican momentos de la vida cotidiana de dichos pueblos fue común sobre todo en el estado de Nayarit, parte de esas escenas que se han dado en llamar maquetas, hacen referencia a contextos de batallas. En una ejemplar ubicado en el American Museum of Natural History se aprecia el momento en que un grupo de guerreros esta en combate con un segundo en lo alto de un cerro. Dos hombres con lanzas y dos músicos se acercan a lo que parece ser es una aldea, esta siendo defendida también por algunos guerreros con lanzas y escudo. (Von Winning, 1996:162).

Un patrón general en los sistemas de armamento representados en estos personajes podría ser el siguiente:

1.- Guerreros con mazos. Este tipo de sistema es el más común y simple. Este tipo de guerreros se caracterizan por sujetar un gran mazo a dos manos y estar protegidos por grandes corazas y cascos. Algunos ejemplos pueden ser vistos en: (Solís, 1998:84,85).

2.- Guerreros con honda. Este tipo de sistema tienen como arma ofensiva la honda y también están solamente protegidos con una coraza y casco aunque existen ocasiones en que el guerreros aparece prácticamente sin ninguna defensa como un ejemplar procedente de las colecciones del Museo Regional de Colima. Este sistema de armamento en especial resulta interesante ya que es poco común encontrarlo en otras manifestaciones del arte mesoamericano (Hassig, 1992:189).

3.- Guerrero con lanza. También encontramos el sistema de guerreros que sujetan lanzas y en ocasiones van protegidos de escudos y corazas como los que se aprecian sobre todo en las maquetas.

Debemos de incluir todas aquellas representaciones de personajes que se encuentran arrojando algún proyectil, específicamente una piedra, sin embargo a este tipo de individuos no los integramos directamente dentro de algún sistema en particular ya que presumiblemente las simples rocas usadas en medio de los combates son un recurso mas no forman parte de un diseño y tecnología militar en específico como podría suceder con las piedras para ser arrojadas con la honda que llevan un trabajo previo y están ligadas indiscutiblemente a la honda. ${ }^{4}$

Esta por demás decir la fuerte asociación con los rituales funerarios de este tipo de imágenes, debo sugerir que un estudio mucho más profundo en torno a las procedencias, características iconográficas podrán determinar muy seguramente no solo los estilos artísticos sino los sistemas de armamento ya no solo del Occidente sino de cada estado donde se reprodujo este tipo de arte, un tema bastante interesante que deberá ser abordado por nuevas generaciones de especialistas en el Occidente de México.

Este artículo es tan solo un acercamiento muy general para realmente entender un fenómeno que hasta ahora se ha dejado muy de lado y que como hemos visto, la guerra al igual que paso con los mayas a mediados del siglo pasado, ya ha alcanzado a Teotihuacan recientemente y quizá no falte mucho para saber que en el Occidente de México también el proceso de institucionalización de la violencia, fuera un factor desafortunadamente importante para determinar muchos de los otros rubros que marcaron la vida de las sociedades del pasado mesoamericano, pero ello solo lo podrán determinar los especialistas de cada región, en el Occidente en materia de militarismo falta todo por hacer.

\footnotetext{
${ }^{4}$ Se sabe que en el México Antiguo se fabricaban piedras redondas especialmente para ser arrojadas con la honda, no eran piedras comunes recolectadas del suelo, es probable que el mismo concepto se diera en el Occidente de México. (Cervera, 2004: 71)
} 


\section{BIBLIOGRAFÍA}

BRANIFF CoRnEJo, B. et, alli, (2004): Introducción a la arqueología del Occidente de México, Universidad de Colima, INAH, México.

Brown M. Kathryn, et. alli, (2003): Ancient Mesoamerican Warfare, M. Kathryn Brown y Travis W Station, eds., Alta Mira Press.

Bueno Bravo I. (2006), "La guerra naval en el Valle de México", en: Estudios de Cultura Náhual, v. 36, México,199-223.

CERVERA OBRegón M., (2003): El sistema de armamento entre los mexicas, tesis de licenciatura en arqueología, ENAH-INAH.

Cervera Obregón M., (2004): "El sistema de armamento entre los mexicas", Arqueología Mexicana, n70, Editorial Raíces, México.

Cervera Obregón M., (2006): “The Macuahuitl An innovative weapon of the Late PostClassic in Mesoamerica", Arms and Armour Journal of the Royal Armouires.

Cervera Obregón M.A. (2007) El armamento entre los mexicas, Anejos de Gladius, 11.

De La Fuente B. (1982):"'Escultura en el Occidente- Periodos Preclásico a Clásico Temprano”, El arte mexicano 3- arte prehispánico III, México, Salvat Mexicana Ediciones.412428.

Fernández R. y DARIA Degara (2005): "La zona occidental en el Clásico”, Historia Antigua de México, v. II, Porrúa, INAH, UNAM, México. 161-201.

García- Des Lauriers, C., (2000): Trappings of Sacred War: The Warrior Costume of Teotihuacan, Thesis for the degree of Masters of Arts in Art History, Riverside, University of California Riverside.

GENDROP P., (1988): Arte Prehispánico en Mesoamérica, Editorial Trillas, México.

HASSIG, R. (1988): Aztec warfare Imperial expansion and political control, University of Oklahoma Press.

HASsig, Ross, (1997) War and society in ancient Mesoamerica. Berkeley

HERREJón, C. (1978): "La pugna entre mexicas y tarascos",Cuadernos de Historia. Universidad Autónoma del Estado de Hidalgo. 11-47.

León Portilla M., (2004): "Estratigrafía toponímica. Lengua y escritura", Arqueología Mexicana, v.XII, n.70, Editorial Raíces, México. 26-31.

López A. y LeonARdo López Luján, (1996): El pasado indígena, Colegio de México, Fondo de Cultura Económica, México.

Ochoa P. y Oscar Orueta, (1994): Sala del Preclásico del Altiplano. Catálogo de colecciones del Museo Nacional de Antropología, INAH, México.

Pohl J., M.D. Polh y Angus Mc Bride.(1991): Aztec, Mixtec and Zapotec Armies, Met at Arms Series No 239, Ospray Publishing.

PoHL J., (2001): Aztec Warrior (1325-1521), Warrior No 32, Ospray Publishing.

RePetto Tío, B., (1993): El desarrollo militar entre los mayas, Bibliografía del Mando. Secretaría de la Defensa Nacional. México.

Shöndube, O. (1994): "El Occidente de México", Arqueología Mexicana, II, n. 9, 18-23.

Solís F. y Mercedes de la Garza (1998): Vida y Muerte. Arte funerario del Occidente de México, Fudación Caixa, Barcelona, INAH.

SugiYama, S., (2002): "Militarismo plasmado en Teotihuacan", en: Ideología, política a través de materiales, imágenes y símbolos. Memoria de la Primera Mesa Redonda de Teotihuacan, INAH, México. 185-209.

TowsEND, R., et alii, (2000): El antiguo Occidente de México, arte y arqueología de un pasado desconocido. The art institute of Chicago. Gobierno del estado de Colima, México. 
Trejo, S. (coord..) (2001): La guerra entre los antiguos mayas. Memoria de la Primera Mesa Redonda de Palenque. Silvia Trejo. Editora. INAH.

Winning H von, (1996): Arte prehispánico del Occidente de México, Phil Weigand y Eduardo Williams (coords.), Colegio de Michoacán, México.

Winning H von (1974): The Shaft Tomb Figures of West Mexico, Los Angeles, Southwets Museum , papers, No 24.

Recibido: $26 / 07 / 2006$

Aceptado: 08/08/2006 